NASA/TM-2010-216070

AIAA-2009-6532

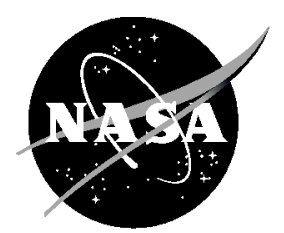

\title{
Cryogenic Fluid Management Technology for Moon and Mars Missions
}

Michael P. Doherty

Glenn Research Center, Cleveland, Ohio

Joseph D. Gaby

Arctic Slope Regional Corporation, Cleveland, Ohio

Louis J. Salerno

Ames Research Center, Moffett Field, California

Steven G. Sutherlin

Marshall Space Flight Center, Huntsville, Alabama 


\section{NASA STI Program . . . in Profile}

Since its founding, NASA has been dedicated to the advancement of aeronautics and space science. The NASA Scientific and Technical Information (STI) program plays a key part in helping NASA maintain this important role.

The NASA STI Program operates under the auspices of the Agency Chief Information Officer. It collects, organizes, provides for archiving, and disseminates NASA's STI. The NASA STI program provides access to the NASA Aeronautics and Space Database and its public interface, the NASA Technical Reports Server, thus providing one of the largest collections of aeronautical and space science STI in the world. Results are published in both non-NASA channels and by NASA in the NASA STI Report Series, which includes the following report types:

- TECHNICAL PUBLICATION. Reports of completed research or a major significant phase of research that present the results of NASA programs and include extensive data or theoretical analysis. Includes compilations of significant scientific and technical data and information deemed to be of continuing reference value. NASA counterpart of peer-reviewed formal professional papers but has less stringent limitations on manuscript length and extent of graphic presentations.

- TECHNICAL MEMORANDUM. Scientific and technical findings that are preliminary or of specialized interest, e.g., quick release reports, working papers, and bibliographies that contain minimal annotation. Does not contain extensive analysis.

- CONTRACTOR REPORT. Scientific and technical findings by NASA-sponsored contractors and grantees.
- CONFERENCE PUBLICATION. Collected papers from scientific and technical conferences, symposia, seminars, or other meetings sponsored or cosponsored by NASA.

- SPECIAL PUBLICATION. Scientific, technical, or historical information from NASA programs, projects, and missions, often concerned with subjects having substantial public interest.

- TECHNICAL TRANSLATION. Englishlanguage translations of foreign scientific and technical material pertinent to NASA's mission.

Specialized services also include creating custom thesauri, building customized databases, organizing and publishing research results.

For more information about the NASA STI program, see the following:

- Access the NASA STI program home page at http://www.sti.nasa.gov

- E-mail your question via the Internet to help@ sti.nasa.gov

- Fax your question to the NASA STI Help Desk at $443-757-5803$

- Telephone the NASA STI Help Desk at 443-757-5802

- Write to: NASA Center for AeroSpace Information (CASI) 7115 Standard Drive Hanover, MD 21076-1320 
NASA/TM-2010-216070

AIAA-2009-6532

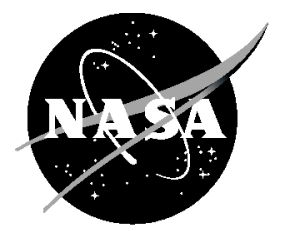

\section{Cryogenic Fluid Management Technology for Moon and Mars Missions}

Michael P. Doherty

Glenn Research Center, Cleveland, Ohio

Joseph D. Gaby

Arctic Slope Regional Corporation, Cleveland, Ohio

Louis J. Salerno

Ames Research Center, Moffett Field, California

Steven G. Sutherlin

Marshall Space Flight Center, Huntsville, Alabama

Prepared for the

Space 2009 Conference and Exposition

sponsored by the American Institute Aeronautics and Astronautics

Pasadena, California, September 14-17, 2009

National Aeronautics and

Space Administration

Glenn Research Center

Cleveland, Ohio 44135 


\section{Acknowledgments}

The authors are deeply appreciative of the NASA-wide CFM Project staff and supporting contractors, without whose tireless work neither would the aforementioned accomplishments have been achieved nor would the Project's detailed future plans have been conceived.

Trade names and trademarks are used in this report for identification only. Their usage does not constitute an official endorsement, either expressed or implied, by the National Aeronautics and Space Administration.

Level of Review: This material has been technically reviewed by technical management.

Available from

NASA Center for Aerospace Information 7115 Standard Drive

Hanover, MD 21076-1320
National Technical Information Service 5285 Port Royal Road Springfield, VA 22161

Available electronically at http://gltrs.grc.nasa.gov 


\title{
Cryogenic Fluid Management Technology for Moon and Mars Missions
}

\author{
Michael P. Doherty \\ National Aeronautics and Space Administration \\ Glenn Research Center \\ Cleveland, Ohio 44135 \\ Joseph D. Gaby \\ Arctic Slope Regional Corporation \\ Cleveland, Ohio 44135 \\ Louis J. Salerno \\ National Aeronautics and Space Administration \\ Ames Research Center \\ Moffett Field, California 94035 \\ Steven G. Sutherlin \\ National Aeronautics and Space Administration \\ Marshall Space Flight Center \\ Huntsville, Alabama 35812
}

\begin{abstract}
In support of the U.S. Space Exploration Policy, focused cryogenic fluid management technology efforts are underway within the National Aeronautics and Space Administration. Under the auspices of the Exploration Technology Development Program, cryogenic fluid management technology efforts are being conducted by the Cryogenic Fluid Management Project. Cryogenic Fluid Management Project objectives are to develop storage, transfer, and handling technologies for cryogens to support high performance demands of lunar, and ultimately, Mars missions in the application areas of propulsion, surface systems, and Earth-based ground operations. The targeted use of cryogens and cryogenic technologies for these application areas is anticipated to significantly reduce propellant launch mass and required on-orbit margins, to reduce and even eliminate storage tank boil-off losses for long term missions, to economize ground pad storage and transfer operations, and to expand operational and architectural operations at destination. This paper organizes Cryogenic Fluid Management Project technology efforts according to Exploration Architecture target areas, and discusses the scope of trade studies, analytical modeling, and test efforts presently underway, as well as future plans, to address those target areas. The target areas are: liquid methane/liquid oxygen for propelling the Altair Lander Ascent Stage, liquid hydrogen/liquid oxygen for propelling the Altair Lander Descent Stage and Ares V Earth Departure Stage, liquefaction, zero boil-off, and propellant scavenging for Lunar Surface Systems, cold helium and zero boil-off technologies for Earth-Based Ground Operations, and architecture definition studies for long term storage and on-orbit transfer and pressurization of $\mathrm{LH}_{2}$, cryogenic Mars landing and ascent vehicles, and cryogenic production via in situ resource utilization on Mars.
\end{abstract}

\section{Nomenclature}

$\begin{array}{ll}\text { ARC } & \text { NASA Ames Research Center } \\ \text { BAC } & \text { Broad Area Cooling } \\ \text { CFD } & \text { Computational Fluid Dynamics } \\ \text { CFM } & \text { Cryogenic Fluid Management }\end{array}$




$\begin{array}{ll}\text { CryoSim } & \text { Cryogen Storage Integrated Model } \\ \text { CTB } & \text { Cryogenic Test Bed } \\ \text { d } & \text { day(s) } \\ \text { EDS } & \text { Earth Departure Stage } \\ \text { ESAS } & \text { Exploration Systems Architecture Study } \\ \text { ETDP } & \text { Exploration Technology Development Program } \\ \mathrm{ft} & \text { foot } \\ \mathrm{ft}^{3} & \text { cubic feet } \\ \text { GHe } & \text { gaseous helium } \\ \text { GRC } & \text { NASA Glenn Research Center } \\ \text { GSFC } & \text { NASA Goddard Space Flight Center } \\ \text { hr } & \text { hour(s) } \\ \text { ISRU } & \text { In Situ Resource Utilization } \\ \text { JSC } & \text { NASA Johnson Space Center } \\ \text { KSC } & \text { NASA Kennedy Space Center } \\ \text { LAD } & \text { Liquid Acquisition Device } \\ \text { lb } & \text { pound(s) } \\ \text { LEO } & \text { low Earth orbit } \\ \text { LCH } & \text { liquid methane } \\ \text { LH } & \\ \text { LLO } & \text { liquid hydrogen } \\ \text { LOx } & \text { low lunar orbit } \\ \text { LSS } & \text { liquid oxygen } \\ \text { MG } & \text { Lunar Surface Systems } \\ \text { MLI } & \text { mass gauge } \\ \text { MHTB } & \text { multi-layer insulation } \\ \text { MMOD } & \text { Multi-purpose Hydrogen Test Bed } \\ \text { MSFC } & \text { Micrometeoroid Orbital Debris } \\ \text { NASA } & \text { NASA Marshall Space Flight Center } \\ \text { NBP } & \text { National Aeronautics and Space Administration } \\ \text { PMD } & \text { normal boiling point } \\ \text { P-V-T } & \text { Propellant Management Device } \\ \text { RBO } & \text { Pressure, Volume, Temperature } \\ \text { RCS } & \text { reduced boil-off } \\ \text { RF } & \text { Reaction Control System } \\ \text { SMiRF } & \text { radio frequency } \\ \text { TankSIM } & \text { Small Multi-Purpose Research Facility } \\ \text { TRL } & \text { Tank System Integrated Model } \\ \text { TVS } & \text { Technology Readiness Level } \\ \text { ZBO } & \text { Thermodynamic Vent System } \\ & \text { zero boil-off } \\ & \end{array}$

\section{Introduction}

NASA's Cryogenic Fluid Management (CFM) Project, under the auspices of the Exploration Technology Development Program (ETDP), focuses on the development of cryogenic storage systems, low-gravity propellant management systems, cryogenic transfer and handling technologies needed to provide necessary data and relevant experience to support informed decisions on implementation of cryogenic systems into the Space Exploration Architecture. The CFM Project is a customer need driven project, emphasizing efforts that are enhancing and critical to NASA's Constellation Program's Projects (Ref. 1). The CFM Project is led by the NASA Glenn Research Center (GRC) in partnership with the NASA Marshall Space Flight Center (MSFC), the NASA Johnson Space Center (JSC), the NASA Ames 
Research Center (ARC), the NASA Goddard Space Flight Center (GSFC), the NASA Kennedy Space Center (KSC), along with industrial partners.

The Exploration Systems Architecture Study (ESAS) (Ref. 2) along with multiple other follow-on study activities have established top level functional and performance requirements for Constellation elements. Constellation spacecraft include Orion, Ares I, Altair, and Ares V. Orion and Ares I are already in development as the means to replace the Space Shuttle, and for the most part do not require cryogenic fluid management technology efforts.

Consequently, the customers of CFM are Constellation elements needed for lunar exploration, Altair, Ares V, Ground Operations, and Lunar Surface Systems (LSS), as well as future defined elements specific to Mars exploration.

Altair, the lunar lander, will provide the capability to insert the crew into low lunar orbit (LLO), carry the crew to the lunar surface, and then return them to LLO (Ref. 3). Multiple engineering analyses and trades have indicated that the overall architecture goals require that the Altair Descent Stage must utilize liquid oxygen ( $\mathrm{LOx}$ )/liquid hydrogen $\left(\mathrm{LH}_{2}\right)$ propellants, making $\mathrm{LOx} / \mathrm{LH}_{2} \mathrm{CFM}$ an enabling technology. The current state of the art duration for $\mathrm{LH}_{2}$ on orbit is up to $10 \mathrm{hr}$, while the current requirement is up to $14 \mathrm{~d}$ (the length of time from Earth launch of Altair until landing of Altair on the Moon). In addition, $\mathrm{LOx} / \mathrm{LCH}_{4}$ is still being traded for use in the Altair Ascent Stage, making $\mathrm{LOx} / \mathrm{LCH}_{4} \mathrm{CFM}$ an enhancing technology. There is no current state of the art in flight systems for $\mathrm{LCH}_{4}$, while the current requirement is up to $224 \mathrm{~d}$ (the length of time from Earth launch of Altair until ascent and lunar rendezvous with Orion).

After Orion is launched atop a human-rated Ares I to low Earth orbit (LEO), Ares V will lift Altair to LEO for rendezvous with Orion. Integral to the Ares V is an Earth Departure Stage (EDS), a restartable stage that performs a portion of the Earth ascent and provides the propulsion to accelerate the Altair/Orion stack from LEO to trans-lunar injection. Studies have indicated that the overall architecture goals require that the EDS must utilize $\mathrm{LOx} / \mathrm{LH}_{2}$ propellants, making $\mathrm{LOx} / \mathrm{LH}_{2} \mathrm{CFM}$ an enabling technology. The current duration state of the art for $\mathrm{LH}_{2}$ on orbit is up to $10 \mathrm{hr}$, while the current requirement for EDS is 4 d.

LSS will include Environmental Control and Life Support Systems (ECLSS), Extra Vehicular Activity (EVA), power and thermal control systems, surface mobility (i.e., rovers), payloads, robotic systems, and In Situ Resource Utilization (ISRU) systems to enable crewmembers to live, work, and explore the surface of the Moon. Considerations for cryogenic fluids and their impact are LOx versus gaseous oxygen (GOx), $\mathrm{LH}_{2}$ versus cold gaseous hydrogen $\left(\mathrm{GH}_{2}\right)$, liquefaction, storage, transfer system/components, propellant scavenging, and slosh control.

Ground Operations will provide support to vehicle processing and launch. As related to cryogenic fluids, the needs are development of technologies to support increased propellant pad capabilities, to provide zero-loss propellant storage, to minimize propellant transfer losses, and to detect leaks to maintain safe launch site operations and minimize transfer losses.

The Mars Transfer Vehicle (MTV) and Descent Ascent Vehicle (DAV) support the Mars missions and will be added to the Architecture in the future. The MTV is used to transport crew from LEO to low Mars orbit. The DAV function is similar to that of Altair; it provides transportation to and from the Martian surface and crew habitat for up to $30 \mathrm{~d}$ while habitation is activated. Studies have pointed to the benefit of cryogenic fluids for Mars exploration.

This paper organizes project efforts in testing, analytical modeling, and trade studies organized according to five Exploration Architecture target areas:

1) $\mathrm{LCH}_{4} / \mathrm{LOx}$ propulsion system for the Altair Lander Ascent Stage,

2) $\mathrm{LH}_{2} / \mathrm{LOx}$ propulsion systems for the Altair Lander Descent Stage and Ares V EDS,

3) Liquefaction, zero boil-off (ZBO) storage, and propellant scavenging for LSS,

4) Cold He and ZBO technologies for Earth-Based Ground Operations, and 
5) Mars architecture propulsion system CFM definition studies for long-term storage, on-orbit transfer, and autogenous pressurization of $\mathrm{LH}_{2}$, cryogenic Mars landing and ascent vehicles, and cryogenic propellant and life support production via ISRU on Mars.

\section{Analytical Tools and Component Technologies}

Prior to discussion of CFM Project technology efforts specifically addressing each of the five Exploration Architecture target areas, a discussion of analytical tools and component technologies, key project efforts with impact on multiple target areas, is provided.

\section{Analytical Tools}

Analytical tools are critical to the prediction of space flight system performance. Analytical tools under development by the CFM Project include tools to support overall mission performance prediction of CFM system/subsystems, cryogenic storage thermodynamic and fluid dynamic modeling tools to predict fluid behavior, and component tools to guide the design of component hardware. A brief overview of the analytical tools being developed by the CFM Project follows.

Cryogen Storage Integrated Model (CryoSIM) is a CFM system/subsystem tool to support overall mission performance prediction of in-space cryogenic storage systems. Its development was driven by the need to standardize and integrate a number of existing NASA cryogenic codes that use various algorithms with varying degrees of documentation, verification, and availability. CryoSIM is an iterative insulation temperature and heating rate solver to model cryogenic tank thermal performance, while interfacing with a Thermal Desktop based vehicle thermal model to predict vehicle temperatures and heat loads. CryoSIM utilizes inputs such as tank geometry and propellant load, material properties, insulation design, internal component (e.g., Thermodynamic Vent System (TVS), Liquid Acquisition Device (LAD), and mass gauge (MG)) details, radiation and conduction sink temperatures, and mission duration, to provide estimates for: insulation mass, layer density, and fluid temperatures, TVS, LAD, and MG mass and input power parameters, heat loads to insulation, supports, and penetrations, and propellant boiloff mass. Although still in development, CryoSIM is being used to support Constellation trade studies.

Tank System Integrated Model (TankSIM) is a lumped node program for modeling TVS characteristics within various tank sizes and geometries. The program will enable rapid turnaround modeling of $\mathrm{LH}_{2}, \mathrm{LOx}, \mathrm{LN}_{2}$ and $\mathrm{LCH}_{4}$ using either a spray bar or axial jet TVS. The self-pressurization segment of the program is complete and the mixer/heat exchanger elements are in progress. TankSIM will be integrated with CryoSIM in 2010.

The focus of the fluid dynamic and thermodynamic modeling effort within CFM project to date has been the cryogenic propellant tanks for Altair and EDS. Fluid dynamics modeling (settling, slosh, equilibrium liquid/ullage interface shape) is considered more mature than thermodynamics modeling and many tools are available, such as: Computational Fluid Dynamics (CFD) codes (Flow-3D, Fluent, CFDACE+), the Dodge SLOSH code (Ref. 4) (lateral sloshing for Bond $>10$ and 2D-axisymmetric), and Surface Evolver (Ref. 5) (equilibrium interface shape/location for various tank geometries and gravity vectors). Thermodynamic modeling has been the main focus of liquid storage analysis, and is being done via both multimode codes and CFD codes to predict cryogenic tank pressure and temperature rise due to representative heat leak rates into the tank. CFD codes under development and validation include Flow3D (Refs. 6 to 9), Fluent (Refs. 10 and 11), and CFD-ACE+. Figure 1 shows the results of a two-phase lumped vapor model (sharp liquid/vapor interface with single node ullage) implemented using a customized version of Fluent (Ref. 12). Important physical phenomena to be modeled by CFD includes: two-phase flow with mass and heat transfer across gas/liquid interface, heat transfer between gas/liquid/wall/penetrations, buoyancy effects, surface tension effects in low gravity (low Bond number), multispecies ullage gas with noncondensable component, turbulence modeling (for high flow Reynolds number for axial jet or spray bar mixing devices), spray modeling (atomization, evaporation/ condensation, drop interactions with solid surfaces, and liquid/ullage interface), and TVS submodels 

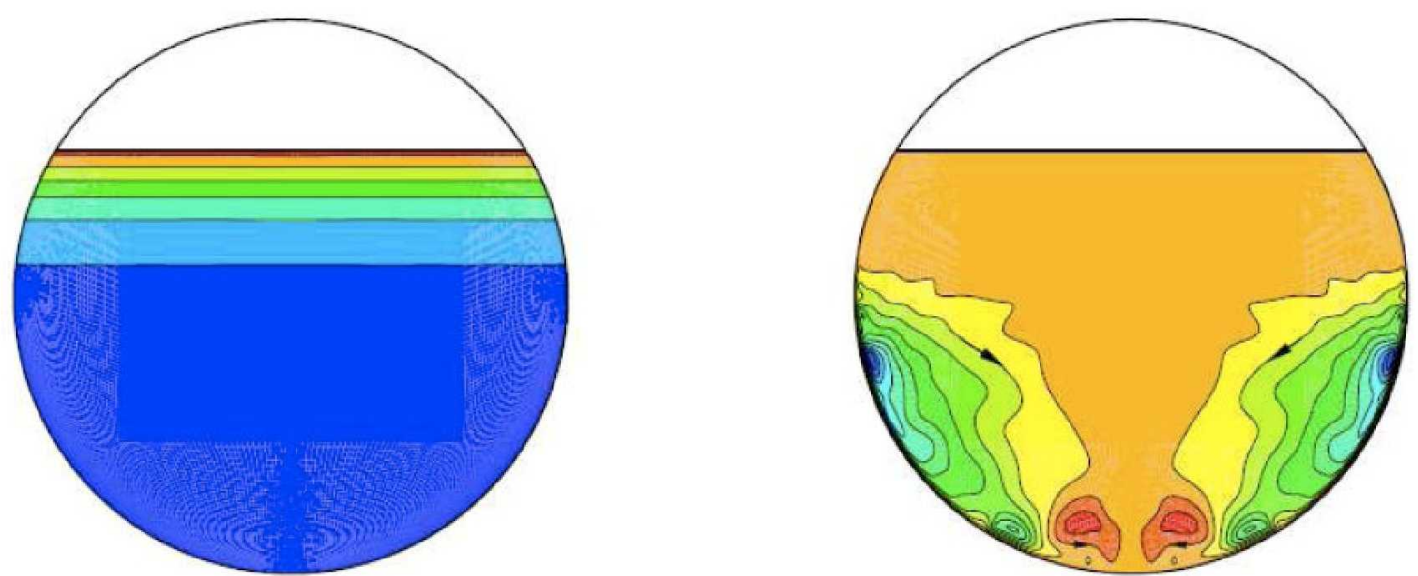

Figure 1.-CFD model temperature (left) and flow (right) fields for methane tank after 2 days on lunar surface.

(pump, JT device, heat exchanger, spray or jet device). The goal is to develop/validate CFD codes using ground-based experiments and limited flight data to predict in-space and lunar surface behavior for Altair and EDS tank design.

Analytical tools are being developed to assist designers in the performance prediction of CFM components/subsystems. Examples of these are cryogenic fluid/helium solubility models, liquid acquisition device screen bubble point predictors, and mass gauge design guides.

\section{Component Technologies}

There are a number of component technologies that affect more than one Exploration Architecture target area. Examples of these are mass gauging (for determination of remaining propellant prior to propellant burn), leak detection (evaluation of the presence and severity of propellant leaks), and cryogenic distribution (piping component hardware and technology to ensure the quality of propellants distributed to the main engine and Reaction Control System (RCS)). Only the mass gauging and leak detection will be discussed here.

Propellant mass gauging is the determination of propellant load. High accuracy mass gauging is desirable to reduce propellant margins that are required for uncertainty in the propellant inventory. There are two general classes of mass gauging - settled gauging and low-g gauging. Settled gauging requires an applied g-load (either through being in a gravity field (e.g., on lunar surface) or through a sustained, albeit, low thrust engine burn), while low-g gauging does not require an acceleration field. The obvious advantage of low-g gauging is that it does not require propellant to be burned, and that it can provide propellant quantity information at any time during a mission. Low-g gauging is a technically challenging problem and will require demonstration in a microgravity environment to prove its technology readiness. Settled gauging approaches include wet-dry point sensors, capacitance probes, and delta-p techniques. Low-g gauging techniques include the Pressure-Volume-Temperature (P-V-T) method and the Radio Frequency (RF) method.

Evaluation of a commercially available liquid level sensing unit, an array of wet-dry point sensors called Cryotracker (Sierra Lobo, Inc.), was conducted in $\mathrm{LH}_{2}$ in April 2009. Testing was conducted to assess the accuracy of the Cryotracker, to gain operational experience with its use, and to independently assess its applicability to exploration vehicle tanks. The test set up included a $7 \mathrm{ft} \mathrm{high,} 17 \mathrm{ft}^{3}, 25 \mathrm{psig} \mathrm{LH}_{2}$ filled dewar placed on a reference weight scale. The Cryotracker probe had twenty sensors and was mounted to a tube mast of the dewar. Preliminary analysis of the data indicate the Cryotracker mass measurement uncertainty to be on the order of 1 to 2 percent of full-scale in a $1-\mathrm{g}$ environment. 


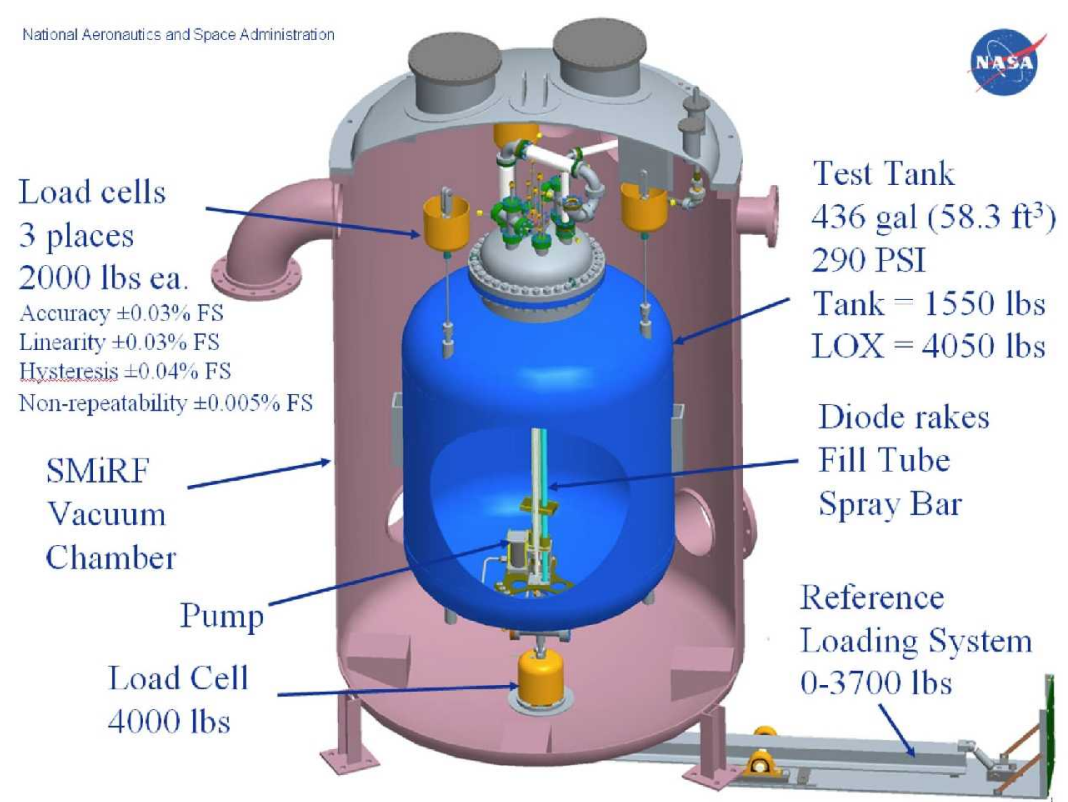

Figure 2. $-58 \mathrm{ft}^{3}$ test tank within SMiRF vacuum chamber that supported LOx P-V-T/RF MG testing.

Evaluation of the Pressure-Volume-Temperature (P-V-T) method of mass gauging was conducted in LOx in August 2007. The P-V-T gauging concept is based on the conservation of the initial gaseous helium (GHe) present in a supply tank, requires the pressure, temperature, and volume be known for both the propellant tank and the GHe supply tank, and assumes both tanks are isothermal and at steady state conditions. As the cryogen is expelled from the propellant tank over time and the GHe supply tank steadily loses pressure, the known mass and density of the makeup GHe in the propellant tank are used to calculate the ullage volume from which the propellant quantity can be determined. The test set up included a $58 \mathrm{ft}^{3}, 250$ psig LOx filled tank suspended by three load cells (for a reference weight measurement) within a vacuum chamber at GRC's Small Multi-Purpose Research Facility (Fig. 2). Analysis of the data indicates the P-V-T measurement uncertainty to be approximately 2 percent of full-scale. The method is applicable to pressure fed applications, is considered low risk for application in low-g environments, and does not require additional instrumentation assuming the flight hardware already will have temperature and pressure sensors and pumps/spraybars for propellant thermal/pressure control.

Evaluation of the radio frequency (RF) method of mass gauging was conducted in LOx in February 2008. The RF mass gauging concept is based upon the presence of a dielectric fluid (hydrogen, oxygen, and methane are all dielectric fluids) slowing the speed of light and altering the electromagnetic eigenmodes of a propellant tank (Ref. 13) The test set up was similar to the P-V-T test-it was conducted in a $58 \mathrm{ft}^{3}, 250 \mathrm{psig}$ LOx filled tank suspended by three load cells (for a reference weight measurement) within a vacuum chamber (Fig. 2). The data indicate a root-mean-square measurement uncertainty of approximately 1 percent of full-scale over a broad range of test conditions. The RF MG technique is applicable to either pressure-fed or pump-fed applications. It offers the potential for high-accuracy gauging even under low-gravity conditions. The technique is not significantly affected by helium pressure, liquid temperature, thermal gradients, spray bar cooling, or tank draining.

Leak detection technology is important because fundamental safety concerns exist associated with the use of propellants before launch, during launch, and while conducting on-orbit and surface operations. The goal is to detect the presence, location, and severity of propellant leaks in a variety of hardware systems and environments prior to an activity (e.g., burn of stage, or rendezvous with crew) that would jeopardize the crew or flight hardware if the leak were undetected. The hardware development approach 
is based on the Smart Leak Detection System (based on the "Lick and Stick" technology presently being qualified for Ares I implementation (Ref. 14)), but tailored and expanded to meet EDS and on-orbit requirements. A test currently underway is to perform a test stand evaluation of the hydrogen sensor technology in conjunction with a thruster testing series. The testing will evaluate the sensors' durability/survivability, calibration stability, false alarm rates, response times, and its performance will be compared with commercial sensors.

\section{$\mathrm{LCH}_{4} / \mathrm{LOx}$ for Propelling the Altair Lander Ascent Stage}

The present Constellation architecture for the Altair Ascent Stage requires the propellants to be loaded atop the Ares $\mathrm{V}$ vehicle at the ground launch site, be maintained in LEO for a maximum of $4 \mathrm{~d}$, transported to a LLO and be conditioned to the pressure fed Ascent Stage main engine start box conditions prior to descent to the lunar surface to be prepared for a mission abort. While on the lunar surface the Ascent Stage propellant fluid conditions must always be maintained within the main engine start box to enable either a nominal or abort ascent. For the Lunar Outpost mission, this requires a propellant storage time of $210 \mathrm{~d}$ at the lunar Pole. The lunar mission environmental conditions, from $1-\mathrm{g}$ to low-g to 1/6-g and temperature operation variations from 380 to $75 \mathrm{~K}$ pose a number of fluid management challenges of long term storage, mass gauging, fluid acquisition (to feed the RCS thrusters in LLO), and propellant conditioning to any Altair Ascent Stage propellant combination. The propellant combination of $\mathrm{LCH}_{4}$ and $\mathrm{LOx}$ is enhancing for use with the Altair Ascent Stage main engine and the RCS thrusters. Prior low gravity and ground support cryogenic fluid management experience with this propellant combination is nonexistent, but current studies and ground testing with $\mathrm{LCH}_{4}$ have shown that the cryogenic fluid management technologies required to support the present Altair Ascent Stage mission with $\mathrm{LCH}_{4}$ and $\mathrm{LOx}$ can be accomplished with low mass and power requirements and minimal operational complexity.

\section{$\mathrm{LCH}_{4}$ and LOx Thermal and Pressure Control}

In fiscal year 2009 the CFM Project funded the Boeing Company to conduct a Lunar Surface Thermal Control study based on NASA's Lander Design Analysis Cycle-1 (LDAC-1) Altair configuration to analyze various thermal control strategies to store $\mathrm{LCH}_{4}$ and $\mathrm{LOx}$ on the lunar surface for the 210-d lunar Pole outpost mission. Each thermal control concept was to be traded versus mass penalty, power requirements, technology readiness level (TRL) and operational complexity. The study concluded that starting with normal boiling point (NBP) propellants and using a passive thermal control concept of thick multilayer insulation (MLI) and thermal strapping the $\mathrm{LCH}_{4}$ tank to the $\mathrm{LOx}$ tank, the total propellant loss due to radiant and conductive heat transfer would be less than $0.9 \mathrm{~kg}(2.0 \mathrm{lb})$ over the 210 day lunar stay and the ratio of the thermal control mass to propellant mass would be less than 0.019. A low power mixer would be required to de-stratify the cryogens. Tank pressure control would be sequentially obtained by initially using the bulk heat capacity of the propellants, mixing and ullage venting on the lunar surface and finally by Thermodynamic Venting System (TVS) venting for propellant conditioning. Using the same thermal control concept and densifying the $\mathrm{LCH}_{4}$ on the launch pad to $90.5 \mathrm{~K}\left(163^{\circ} \mathrm{R}\right)$ results in the total propellant loss due to radiant and conductive heat transfer being less than $0.68 \mathrm{~kg}(1.5 \mathrm{lb})$ over the $210 \mathrm{~d}$ lunar stay and the ratio of the thermal control mass to propellant mass less than 0.014 . NASA will authenticate the study's predicted fluid boil-off and tank pressure rise rate during a test series conducted in the late fall of 2009 at the GRC SMiRF vacuum facility using an Altair LDAC-1 $\mathrm{LCH}_{4}$ flight representative tank (Fig. 3). Ball Aerospace Technology Corporation, through a competitive procurement has designed and fabricated a 60-layer MLI system for the tank. An extensive analytical modeling effort of the tank, its support structure and penetrations has been developed by the CFM Project to predict the total system heat leak and the tank pressure rise rate. Once validated with test data from the test, the analytical model will be used to predict the system heat leak for alternative tank structural support systems, various tank penetrations and MLI degradation due to lunar dust. 


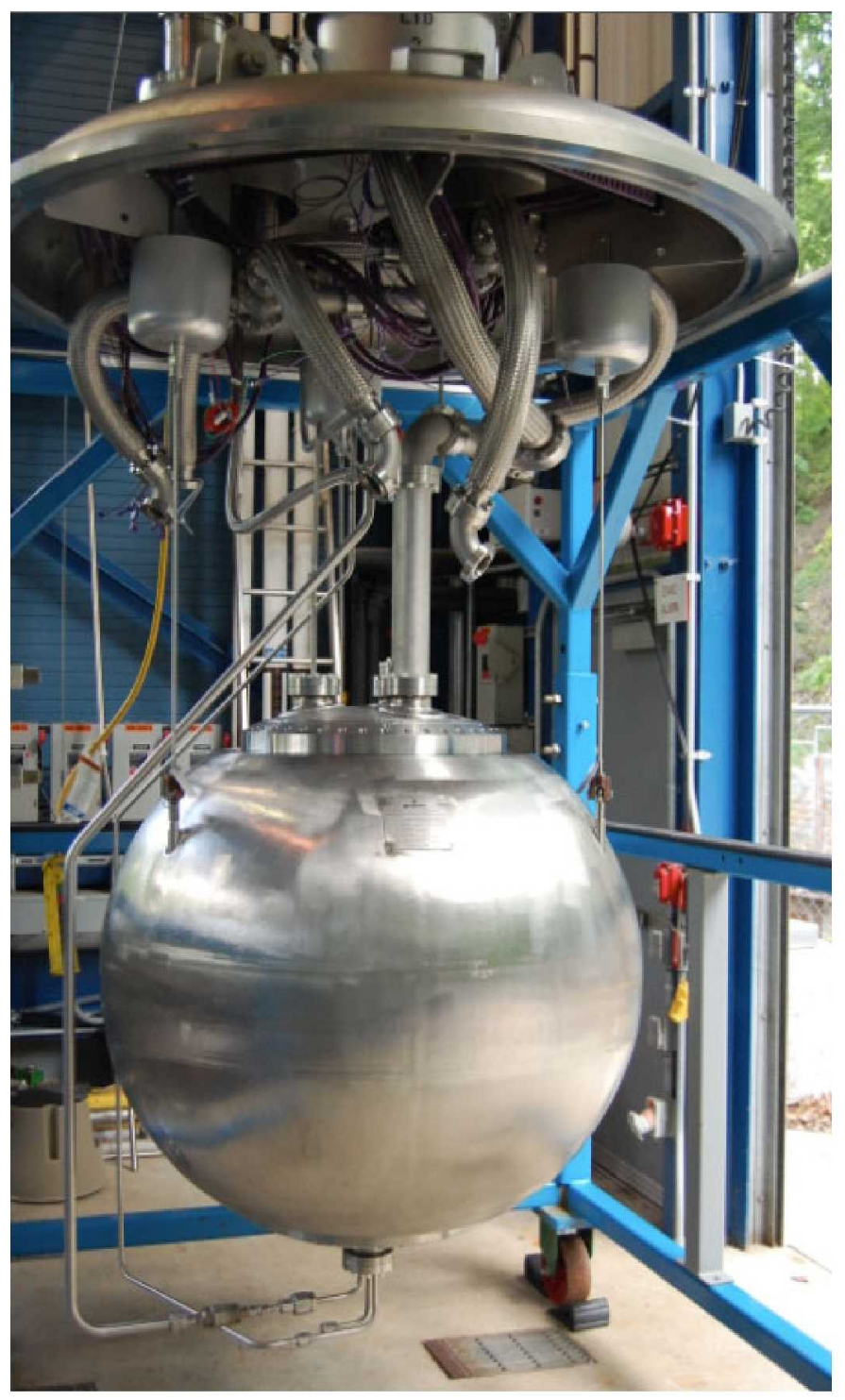

Figure 3.-Altair LDAC-1 flight representative test tank integrated with SMiRF vacuum chamber lid.

Tank pressure control of cryogenic propellants in low gravity can be achieved either through settling of the vehicle's propellants and employing a nonpropulsive vent or through the use of a TVS. Current studies have shown that the Altair Ascent Stage propellant tanks will not be required to vent propellant during the short low-g portion of the mission because of the number of MLI layers required for the long lunar stay portion of the mission, however a TVS is under consideration to provide a propellant conditioning capability. The CFM Project has concluded the following TVS technology tasks:

Verified through $\mathrm{LOx}$ and $\mathrm{LCH}_{4}$ testing at Altair Ascent Stage propellant tank conditions that a wide range of Joule-Thomson devices used in the TVS will not "clog," impacting the TVS heat removal performance (Ref. 15).

Investigated the TVS performance of both a spray bar and axial jet in LOx at Altair Ascent Stage propellant tank conditions (Ref. 16).

Investigated the TVS performance of a spray bar in $\mathrm{LCH}_{4}$ (Ref. 17). 
In addition, a CFD model analyzing the performance of both a spray bar and the axial jet TVS has been completed (Ref. 18).

\section{$\mathrm{LCH}_{4}$ Densification}

Supplying densified $\mathrm{LCH}_{4}$ to the Altair Ascent Stage at the launch pad at $90.5 \mathrm{~K}\left(163^{\circ} \mathrm{R}\right)$, (the same temperature as the LOx) would allow for a greater heat capacity for the $\mathrm{LCH}_{4}$ and $\mathrm{LOx}$ propellant combination at a negative mass impact to Altair. The CFM Project is conducting a trade study to determine the feasibility and appropriate launch site architecture for delivering densified methane to Altair. This study will be concluded in mid 2010.

\section{$\mathrm{LCH}_{4}$ and LOx Propellant Management}

The present Altair Ascent Stage configuration utilizes a common propellant combination for both ascent from the lunar surface with the main engine and rendezvous and docking with Orion in LLO with the RCS. The propellant tanks will be pressurized with helium to maintain a near constant tank pressure during the lunar ascent. Vapor free fluid must be delivered to the propulsion systems for any propellant combination. During lunar ascent the propellant will be settled at the tank outlet to supply the main engine but during the LLO maneuvers a propellant management device (PMD) will be required for liquid acquisition. For the $\mathrm{LCH}_{4}$ and $\mathrm{LOx}$ propellant combination, an innovative screen sump PMD concept was proposed by the NASA CFM community. The PMD traps liquid and utilizes the capillary force of a dutch twill fine mesh screen LAD to provide liquid only to the RCS during the omni-g LLO maneuvers. The CFM Project has concluded or is nearing conclusion on the following cryogenic fluid acquisition technology tasks:

- Measured the "Bubble Point" pressure (defined as the differential pressure across the screen that overcomes the surface tension of the liquid on the screen) of both subcooled $\mathrm{LCH}_{4}(\operatorname{Ref} .19)$ and LOx

- Investigated the effect of heat entrapped in a screen channel LAD due to engine soak-back or parasitic tank heating (Ref. 20)

- Investigated the effects of performance degradation of a screen channel LAD due to long term helium solubility in LOx. (Fall 2009)

- Measured the flow "rangeability" of a screen channel LAD to permit both the high continuous flow rate required by the Ascent Stage main engine and the short intermittent flow rate required by the RCS thrusters through a single LAD channel. (Fall 2009)

In addition a CFD thermal model of the screen sump PMD concept has been completed (Ref. 20).

In fiscal year 2009 the CFM Project funded Innovative Engineering Solutions, Inc (IES) through a competitive procurement to develop an independent PMD concept based on NASA's LDAC-1 Altair Ascent Stage configuration (Ref. 21). IES down-selected two PMD types, one is a traditional partial fourscreen channel device and the other type is a novel, expanding volume device that makes use of a stretched, flexing screen. The two selected concepts satisfied all the Altair Ascent Stage design requirements provided by NASA. Further development of the stretched, flexible screen is planned in 2010. Excerpted from the IES final report is the following statement: "A significant finding was that advantage could be taken of unique descent and ascent stage design features to simplify the PMD designs. These features are 1) high propellant tank operating pressures, 2) high thermal conductivity aluminum tanks for propellant storage, and 3) stringent insulation requirements. Consequently, it was possible to treat $\mathrm{LOx}$ and $\mathrm{LCH}_{4}$ as if they were equivalent to Earth-storable propellants because they would remain substantially subcooled during the lunar mission: boiling and vapor formation would become nonissues." 


\section{$\mathrm{LCH}_{4}$ Integrated Testing}

The performance of each Altair Ascent Stage propellant tank fluid management component and subsystem required for the Constellation lunar mission must not degrade when integrated as a system. The CFM Project in 2011 will demonstrate the integrated performance with $\mathrm{LCH}_{4}$ using "prototypical" CFM components and subsystems in a flight representative Altair Ascent Stage propellant tank. The term "prototypical" implies test hardware beyond laboratory hardware and will infuse all component and subsystem advanced development tasks accomplished under the CFM Project. The objective of this test program is to characterize the interrelationships of the CFM components and subsystems and observe their overall integrated performance at nominal Altair Ascent Stage mission operational conditions. This test will evaluate the affect of significant variations (expected to occur during nominal Altair mission operations) in the tank fluid state properties, thermal environments and fluid dynamics (mixing, outflow and level) on the CFM technologies within a $\mathrm{LCH}_{4}$ filled tank, which could compromise individual CFM component and/or subsystem performance. Characterizing the combined influence of the CFM subsystems on component performance in a fully integrated system test is a development need.

\section{$\mathrm{LH}_{2} / \mathrm{LOx}$ for Propelling the Altair Lander Descent Stage and Ares V EDS}

$\mathrm{A} \mathrm{LH}_{2}$ and LOx propulsion system is enabling for the Altair Descent Stage and the Ares V EDS. While on-orbit flight durations have been relatively brief (our experience with $\mathrm{LH}_{2}$ is limited to $<10 \mathrm{hr}$ after launch (Ref. 22)), the flight data on $\mathrm{LH}_{2} / \mathrm{LOx}$ upper stages (Centaur, Saturn S-IVB, and Delta stages) in combination with an extensive history of ground-based testing provides a strong technology database for resolving CFM technology issues uniquely associated with lunar exploration. (The comprehensive MLI data historic data base (1965 to 1990) (Refs. 23 to 41) combined with the more recent Multipurpose Hydrogen Test Bed testing (Refs. 42 and 43) form a solid MLI technology point-ofdeparture. Similarly, Thermodynamic Vent Systems have a strong historic technology base (Refs. 44 to 49) complemented by more recent efforts (Refs. 50 to 62).) Nevertheless, for storage and extended duration use of $\mathrm{LH}_{2}$ on orbit there are technical areas requiring focused attention: ensuring TVS reliability, development of low heat leak, high certainty MLI, investigation of propellant tank heat loads during ascent, evaluation of pressure control methodologies for large scale tanks, investigation of active cooling as an option to passive cooling, and integrated $\mathrm{LH}_{2}$ tank/feedsystem testing.

\section{$\mathbf{L H}_{2}$ TVS Joule-Thomson Clogging Mitigation}

Reliable operation of TVS is deemed critical to maintaining cryogens at appropriate temperatures and pressures for efficient storage and for appropriate inlet conditions to the Altair Descent Stage and EDS engines. Heat leak into cryogenic tanks causes boiling and an undesirable increase in tank pressure. While not eliminating the heat leak, a TVS can control pressure even when the location of vapor is unknown in low gravity and direct venting would be wasteful (Ref. 63). The TVS employs a Joule-Thomson (J-T) valve to expand a small amount of cryogen, which, once the resulting vapor is routed through the cold side of a heat exchanger within the cryogenic tank before being dumped overboard, effectively reduces the temperature (and ullage pressure) within the tank.

Previous experimental investigations have indicated that J-T devices may become clogged when flowing $\mathrm{LH}_{2}$ while operating at a temperature range from 20.5 to $24.4 \mathrm{~K}$. It has been proposed that clogging is due to a trace amount of metastable, super-cooled liquid neon in the regular $\mathrm{LH}_{2}$ supply. In time, flow blockage occurs from accretion of solid neon on the orifice. This clogging poses a realistic threat to spacecraft propulsion systems utilizing J-T devices in cryogenic pressure control systems. TVS failure due to J-T clogging would prevent removal of environmental heat from the propellant and potential loss of mission. Tests were performed in $\mathrm{LH}_{2}$ in February 2009 in the expected Altair Descent Stage operating regime, and clogging was observed. Clogging mitigation strategies investigated were: heaters on the J-T device, flow cycling, a controllable J-T needle valve, redundancy in devices, and 
subcooling of the $\mathrm{LH}_{2}$. The results of this investigation were positive in determining successful mitigation approaches, and recommendations provided for dealing with clogging (Ref. 64).

\section{$\mathbf{L H}_{2}$ Thermal Control}

On-orbit use of $\mathrm{LH}_{2} / \mathrm{LOx}$, required for Trans Lunar Injection of the Altair/Orion stack as well as descent of Altair to the lunar surface, demands low heat leak, high certainty MLI. An innovative MLI was tested using MSFC's Multipurpose Hydrogen Test Bed (MHTB). The performance of a foam/MLI combination on a $10 \mathrm{ft}$ diameter cylindrical tank was tested (Refs. 42 and 43). The spray-on foam was similar to that used on the Space Shuttle external tank. The 45 layer MLI innovative features included a variable radiation layer density, larger but fewer radiation shield perforations for venting, and use of a commercially established roll-wrap installation process that resulted in a virtually seamless MLI. Orbital simulation testing demonstrated that the concept reduced heat leak by about half compared with the best previously tested MLI. Also, compared with a helium purge bag system, the foam substrate reduced ground-hold heat leak and enabled the use of a less complicated $\mathrm{GN}_{2}$ payload bay-type purge. Rapid evacuation testing which simulated the Shuttle ascent profile demonstrated structural integrity and venting.

Although the assessment of the MLI historical database is yet to be completed, the following additional efforts are deemed required for on-orbit $\mathrm{LH}_{2}$ thermal control: 1) minimize performance deviations due to MLI fabrication and installation techniques, 2) standardize analytical modeling of ascent venting, and 3) assure that blanket performance estimates can be applied to both large ( $30 \mathrm{ft}$ diameter) and small tanks. Heat leak uncertainty for tank-applied MLI can occur due to a combination of factors such as MLI seams and penetrations, variations in the MLI fabrication and installation techniques, ascent venting, and "fluffing" in low gravity. These factors have generally resulted in a need to double the estimated heat leak value to determine the MLI layers for a tank-applied system.

In 2010, a 2-yr effort kicks off to reduce MLI performance uncertainty due to MLI fabrication techniques, installation and attachment schemes for large-scale $\mathrm{LH}_{2}$ tanks. A complete historical data base assessment of MLI, including: history and overview of MLI technology, material and fabrication technology, performance modeling, measurement, testing and best practices, and relevant applications and programs - tested, flown and studied - will be undertaken, and an extensive $\mathrm{LH}_{2}$ calorimeter evaluation of up to 20 coupons will be conducted to investigate, at a minimum, the effects of number of MLI layers, layer density, and fabrication and installation techniques on MLI heat leak.

Significant uncertainty and variability exist in the transient heating rates during launch ascent. MLI is not effective until it is evacuated, i.e., the MLI interior pressure must be down to $10^{-5}$ torr. Typically the MLI gases to be vented have two sources, residual purge gases or material outgassing. Therefore, thermal energy added to the $\mathrm{LH}_{2}$ after tank lockup and during MLI ascent venting can be substantial and must be considered in estimating mission boiloff. The problem is predicting how much the MLI interior pressure lags the external ambient pressure, especially after free molecular flow begins. Considerable analytical and testing efforts on ascent venting are documented in the historical database, but standardization of MLI venting analyses techniques appears to be lacking. In 2011 , a multiyear effort is initiated to evaluate ascent venting performance of the insulation system in thermal vacuum environment. An assessment will be completed to identify insulation system configuration and space vacuum venting options based on the MLI historical database for application to large tanks. The task will culminate in the application of state of the art, instrumented MLI to the Cryogenic Test Bed (CTB) test tank (Fig. 4) which in 2014 will be tested in the $15 \mathrm{ft}$ vacuum chamber at the MSFC Test Stand 300 under simulated ascent conditions to evaluate venting performance of the insulation system. 


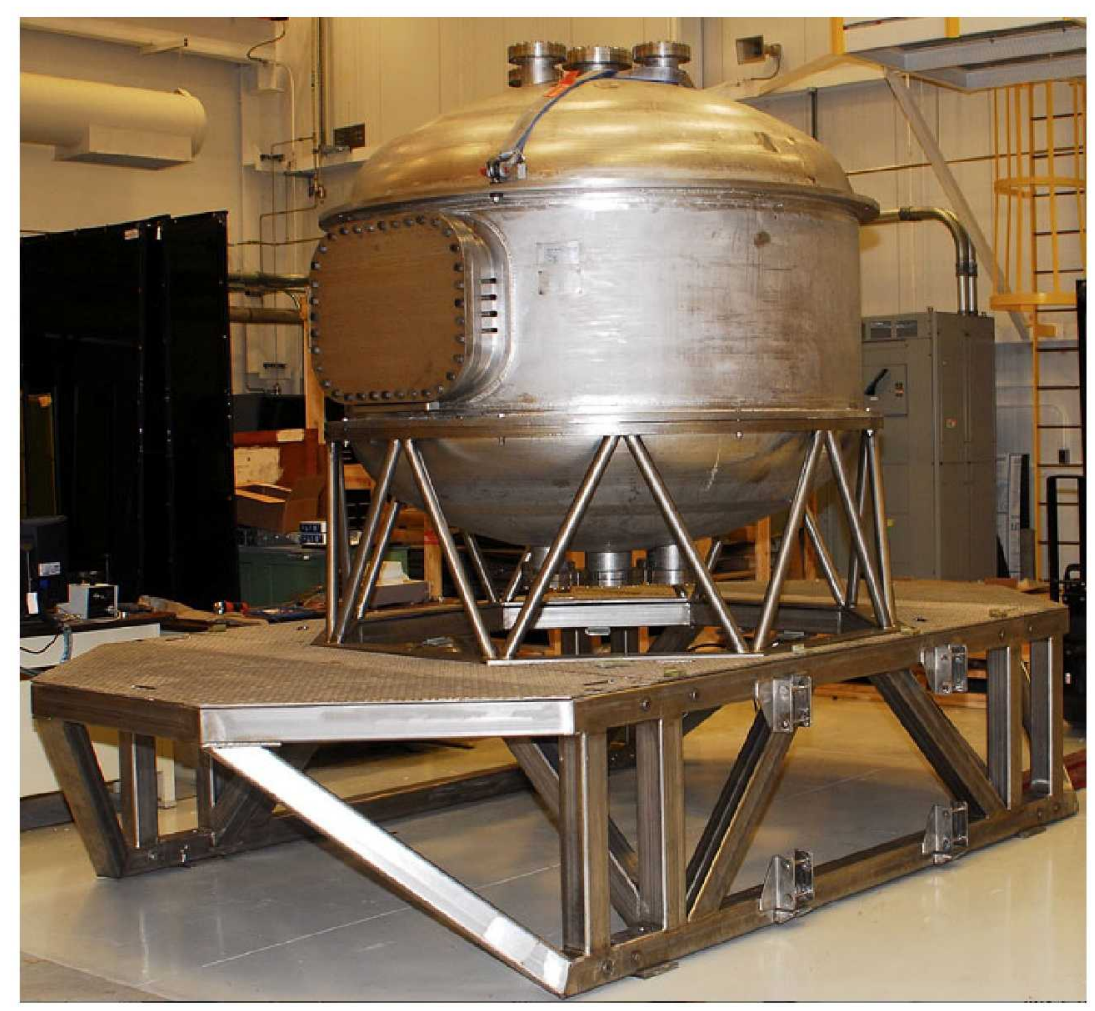

Figure 4.-CTB tank with stand at MSFC.

Large scale MLI systems as required for the Ares V present a challenge to the MLI design engineers, as generally the only available test data is for coupons and the results are scaled up to the large propellant tanks. The CFM project plans to infuse coupon/calorimetry-developed MLI technology into a large scale insulation system. Beginning in 2012, the requirements for a tank-applied MLI system will be developed based upon the latest concept for the EDS, and a high performance durable MLI system will be designed and fabricated. In 2014, a demonstration will be conducted to evaluate ground hold, ascent venting, on orbit thermal performance of the insulation system in thermal vacuum environment.

\section{$\mathrm{LH}_{2}$ Pressure Control for Large Scale Tanks}

The TVS concept for enabling on-orbit pressure control/venting without propellant settling is close to being technology ready for application to space-based cryogenic propulsion systems. About $2100 \mathrm{hr}$ of TVS technology testing was reported between 1967 and 1975 (Refs. 44 to 47), and included both $\mathrm{LH}_{2}$ and LOx propellants. In the 1984 to 1987 timeframe, a high flow-rate single-fault tolerant TVS was developed for the $\mathrm{LH}_{2}$ tank on the Centaur G-Prime upper stage for the Space Shuttle (Refs. 48 and 49). Sufficient qualification testing was accomplished to demonstrate that the unit performed as designed. More recently, over $3900 \mathrm{hr}$ was accomplished in the 1999 to 2005 time-frame (Refs. 50 to 55) and included both axial jet and spray bar mixer concepts, tank diameters ranging from 5 to $10 \mathrm{ft}$, and $\mathrm{LH}_{2}$ and $\mathrm{LN}_{2}(\mathrm{LOx}$ simulant) as test fluids. Automated pressure control was addressed with all test conditions including tank heat inputs ranging from 50 to $400 \mathrm{~W}$ and with/without helium pressurant. Analytical modeling efforts are represented by one report in 1988 (Ref. 56) and six papers or reports between 2006 and 2008 (Refs. 57 to 62). Nevertheless, these tests have not been of sufficient scope to allow their results to be scaled up with confidence to the very large tank size of the EDS. Recent scaling study results show TVS technology advancement is critically needed to meet large-scale, long duration, storage requirements with minimal/zero cryogenic losses. Beginning in 2010, key nondimensional parameters critical to TVS scaling to very large tank sizes will be identified, gaps will be determined in the nondimensional 
parameter range spanned by existing experimental database, and CFD analysis will be performed to investigate scaling effects and sensitivity to key nondimensional parameters. Then, TVS hardware will be added to and tests will be conducted in two geometrically-similar but different-sized tanks (CTB and MHTB) to provide TVS scaling data to update nondimensional scaling relationships and CFD models to provide tools to the flight project for design activities.

\section{$\mathrm{LH}_{2}$ Active Cooling}

Active cooling is an option for ZBO or Reduced Boil-Off (RBO) of $\mathrm{LH}_{2}$ for the Altair Descent Stage. High efficiency flight qualified cryocoolers presently exist for oxygen $(90 \mathrm{~K})$ and methane $(112 \mathrm{~K})$ temperatures, but hydrogen temperature $(20 \mathrm{~K})$ cryocoolers in the capacities required for ZBO systems ( 5 to $20 \mathrm{~W}$ ) do not presently exist. One option is to utilize $90 \mathrm{~K}$ cryocooler technology to cool gaseous helium, which is then circulated throughout the tank's MLI (thermal shield) utilizing a distributed cooling line bonded to the tank's thermal shield. The CFM Project has demonstrated the thermal performance of just such a distributed cooling line bonded to a tank thermal shield. A foil shield test panel bonded at midline to cooling tube and held within a thermal shroud to maintain an isothermal environment was successfully cooled while the shroud saw a constant heat load. A Gifford-McMahon cryocooler provided the cooling for the helium stream. This testing has validated previously developed Broad Area Cooling modeling (BAC) correlations for distributed cooling tubes attached directly to tank thermal shields. (Earlier, distributed cooling was demonstrated for the case of applying the cooling tube directly to the tank, a technology applicable to a warmer cryogen such as $\mathrm{LCH}_{4}$ (Ref. 16)).

\section{$\mathrm{LH}_{2}$ Integrated Testing}

The performance of each Altair Descent Stage propellant tank fluid management component and subsystem required for the Constellation lunar mission must not degrade when integrated as a system. In 2012, the Project will demonstrate the integrated performance with $\mathrm{LH}_{2}$ using prototypical components and subsystems utilizing a complete mission simulation beginning with launch pad loading and launch, and ending with the final engine burn during lunar landing. The tank system will contain all CFM elements including: the pressurization diffuser, slosh baffles, anti-vortex device, propellant utilization instrumentation, a TVS, mass gauging, and a simulated Altair Descent Stage feed/pump system. Tank external hardware includes the foam and MLI that is expected to be specified pending completion of the thermal control system testing. Some new facility provisions will be required, including: the capability to provide conditioned helium and autogenous pressurization $\left(\mathrm{GH}_{2}\right)$ at required flow rates. Also, the accommodation of a larger $\mathrm{LH}_{2}$ expulsion rate will be necessary to simulate Altair Descent Stage flow rates as closely as possible. The anticipated sequence of events is as follows: 1) perform boil-off testing to calibrate insulation characteristics and anchor insulation analytical modeling including ground hold, ascent, and orbit, 2) simulate tanking and ground hold operations including performing tank lock-up according to projected mission timeline, 3) demonstrate MLI structural integrity and venting and ullage pressure control as will be experienced under launch and ascent, 4) simulate Earth orbit coast and translunar coast while conducting TVS pressure control, 5) perform 1st engine start/burn sequence including prepress sequence and $\mathrm{LH}_{2}$ expulsion, 6) simulate lunar orbital coast to demonstrate pressure and liquid temperature control, TVS operations and control algorithm, and 8) perform 2nd engine start/burn sequence beginning at 50 percent fill level and continuing to end of burn/landing sequence.

\section{Liquefaction, ZBO, and Propellant Scavenging for LSS}

Cryogens are envisioned for use on the lunar surface as propellants, fuel cell reactants, and breathable gases. ISRU processing is expected to provide gas streams which can either be stored at high pressure or liquefied and stored as cryogens. Recent technological advances in mechanical coolers to reduce mass and increase efficiency while extending operating lifetimes to $10 \mathrm{yr}$ and longer make liquefaction and 
efficient ZBO storage increasingly attractive. Removing residual propellants from Altair descent tanks will provide additional cryogens for life support and power generation.

\section{LSS Trade Study}

LSS has the following six domains, or elements: ECLSS, EVA, ISRU, mobility, power, and thermal. Below a certain storage quantity, gaseous storage to support these Elements is the most efficient, while above a certain tank size there are distinct advantages to using liquid storage. An additional driver is the tank dormancy period. The goals of the study are to bound the marginal benefit regions, and to create graphs/tables that indicate for each lunar surface system element where using cryogen liquid storage is an option. Beyond this, other factors, such as system complexity and thermal uncertainties, play a factor. For example, cryogen liquid storage could reduce mass and volume, yet might not be optimal.

To optimize the LSS Cryogenic System, the CFM community will look at a common CFM storage system for LSS architecture. Lacking just such a system, one of the study deliverables will be a notional concept of a common system. To conduct the study, basic fluid system requirements will be collected for each LSS element. Examples include inlet/outlet conditions, flow rates, mission needs (quantities), and other system specific parameters (power use, expected thermal environment, etc.) as appropriate. Also required is a list of consumable commodities for consideration. (As an example, fuel cells may need $\mathrm{O}_{2}$ and $\mathrm{H}_{2}$, but ECLSS will also need $\mathrm{N}_{2}$.) Considerations include: mass/volume/power savings for each element, high pressure gaseous tanks versus low pressure liquid tanks, power to liquefy versus compressor power (ECLSS/EVA), and power to preserve cryogen with active cooling.

The study team will determine scaling numbers for CFM options, and make educated guesses for non-CFM options. CFM technology gaps will be identified and added to the CFM project's portfolio for development. Those systems that make the most sense for more focused analysis will be identified, and a follow-on trade study is planned for FY10 dealing with liquefaction.

\section{Liquefaction}

Constellation LSS architecture requires that the liquefaction, refrigeration, densification (where applicable) and storage technologies for cryogens be refined and demonstrated.

One of the first steps is to analyze, develop, and demonstrate a lunar radiator and shield. The shield should protect the thermal surfaces of cryogenic tanks for propellant, life support, and power reactant storage from both solar heat and that emanating from the lunar surface. It should also isolate the tanks from a deep space view. The approach for achieving this involves performing subscale liquefaction tests using gaseous oxygen to determine achievable condensation rates at the expected shielded environment temperatures. A thermal model will be developed by analyzing lunar surface at the Pole, modeling both shielded and unshielded louvers, configuring cold spot radiators, and considering in-situ radiators where they make sense. This will be followed by test hardware definition, design, and a model validation test currently planned for November 2012.

In parallel with this effort is the development of an integrated refrigeration and storage (IRAS) system capable of performing zero boil off storage, densification, and liquefaction. The goal is that densification of LOx be capable of achieving uniform bulk temperatures down to $80 \mathrm{~K}$ and that the liquefaction have a thermodynamic efficiency of 20 percent. The approach will be to test the thermo fluid behavior of a LOx storage tank with a simulated DC cycle cryocooler cold head integrated into the liquid or vapor space of the tank. The stratification and free convection heat transfer coefficient will be characterized and a liquefaction efficiency test is currently planned for September 2012.

The end goal of the analytic and development efforts discussed above is an Integrated Liquefaction, Storage, and Transfer Demonstration. This will demonstrate liquefaction, storage and transfer in an appropriate thermal and vacuum environment and will prove the ability to efficiently liquefy and transfer fluids on the lunar surface for LSS. This test is currently planned for November 2015. 


\section{Propellant Scavenging}

After the Altair lands on the lunar surface, residual propellants will remain in the Descent Stage tanks. A multicenter NASA team has performed preliminary analyses to determine the feasibility of extracting (scavenging) the residual propellants for purposes of supplying reactants to the fuel cell power system and oxygen to the ascent vehicle life support system. Challenges involving use of the residual propellants include removing the inert gas pressurant while assuring the residual propellant remains in the tanks, delivering the residual propellant to the fuel cells and life support system at a defined rate and pressure, and storing and transferring water produced by the fuel cells in a manner which is mass and energy efficient.

As one of the first steps in the scavenging analysis, individual Descent Stage propellant tank heat loads were generated for the Lunar Polar and Lunar Equatorial environments using a Thermal Desktop model of the Altair Lander Design Analysis Cycle-2 (LDAC-2) configuration. Thermal radiation heat loads and radiation interchange factors were generated with Thermal Desktop's RadCAD radiation analyzer, using appropriate orbital definition inputs for the lunar polar and lunar equatorial landing sites. The radiation model included an explicitly defined local lunar surface which interacted with the spacecraft and the local thermal environment. It was modeled as a single-sided $200 \mathrm{~m}$ diameter disk with an absorptivity of 0.87 and an emissivity of 0.97 . Typical temperature results are shown in graphical form in Figure 5. Further analyses are in process and expected to be matured as mission scenarios and requirements evolve.

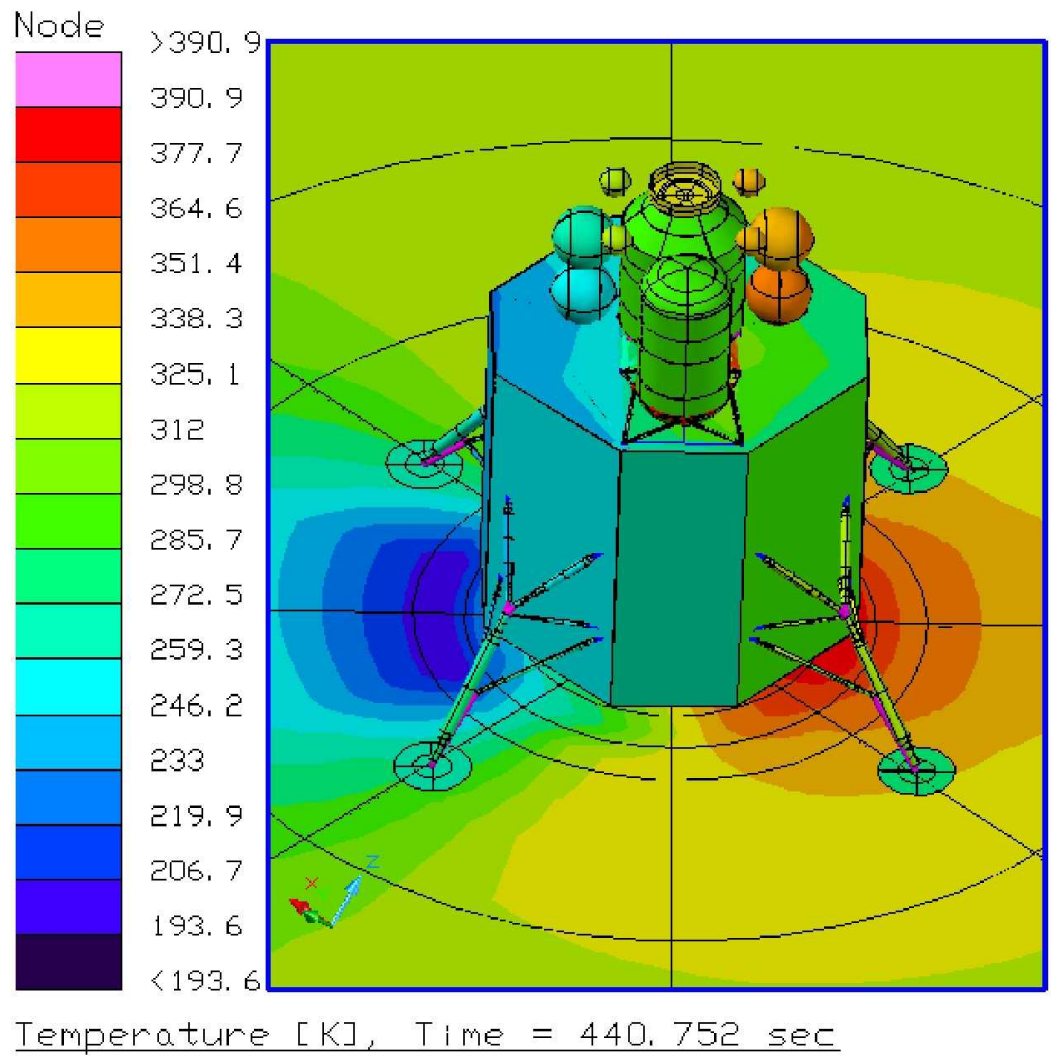

Figure 5.-Typical temperature results, Altair LDAC-2 on the lunar surface. 


\section{Cold Helium and ZBO Technologies for Earth-Based Ground Operations}

To have an efficient lunar surface infrastructure requires an optimized terrestrial ground operation. Constellation elements plan to service cold helium for propellant pressurization using a high pressure helium source and $\mathrm{LH}_{2}$ boiling bath heat exchanger. This approach is thermodynamically inefficient, massive, and increases the amount of hydrogen required at the launch pad. Technology development is currently underway for fluid conditioning of cold helium. The objective is to develop an alternate servicing system that is operationally efficient, requires less hydrogen, and reduces both mass and volume footprints on the launch tower. The approach will be to develop a portable, liquid based pump system capable of supplying moderate pressure gas for tank prepressurization. Technology issues include wear on pump piston seals during operations, thermal transients, pump efficiency, and downstream vaporizer development. A proof of concept test will be performed followed by a ground demonstration test of storage tank pressurization and propellant tank prepressurization on a relevant scale. It is planned to extend the capability to include high pressure gas for bottle fill. The demonstration of tank pressurization is currently planned for June 2011.

The problem of boil-off of cryogens from ground storage tanks will be addressed. Previous work (Ref. 65) has shown that the hydrogen storage tanks at Launch Complex 39A and 39B at the KSC lose $650 \mathrm{~kg}$ (500 gal)/day through boil off. Large scale $\mathrm{LH}_{2}$ and LOx vent losses are not only cost inefficient, but will not allow meeting the Constellation architecture requirement of multiple Ares $V$ launches within a fixed time period. Current operations are unable to support more than four launch attempts per week of Ares V. The technology objective then, is to develop zero loss $\mathrm{LH}_{2}$ and $\mathrm{LOx}$ launch site storage, to eliminate transfer line fluid heating, and to reliably transfer LOx. The approach will be to develop a ground based refrigeration system to reliquefy the hydrogen and oxygen boil off gases, improve $\mathrm{LH}_{2}$ pump efficiency and transfer line conditioning, and develop noninvasive transfer line pressure and flow sensors. The refrigeration hardware, pumps, and transfer line segment will be integrated into a scaled launch site test facility, and a ground operation will be demonstrated. The demonstration will include simulated vehicle hydrogen propellant loading and high reliability LOx transfer. A propellant loading demonstration is currently planned for April 2014 and a high reliability LOx transfer demonstration is planned for July 2015.

\section{Mars Architecture Definition Studies}

The Cryogenic Fluid Management technology developed for the lunar missions will provide valuable data and insight in the development of the CFM technology requirements to support the Mars mission architecture. With a proposed $500 \mathrm{~d}$ total Mars mission time the emphasis will be focused on the reliability and integrated health management of the lunar mission developed CFM technologies of low-g and settled mass gauging, TVS operation in low-g, TVS scaling to EDS sized propellant tanks, thick MLI insulation systems, Micrometeoroid Orbital Debris (MMOD)/MLI integration and leak detection. Several "new" CFM technologies not developed for the lunar missions will be required to enable the Mars architecture. These "new" technologies include active thermal control for long term storage incorporating robust, $\mathrm{LH}_{2}$ cryocoolers integrated into the thermal control system of the $\mathrm{LH}_{2}$ Mars transit propulsion system propellant tank and support structure, on-orbit transfer of cryogenic fluids in LEO, and an efficient, low-g autogenous $\mathrm{LH}_{2}$ tank pressurization system. The assumption of a cryogenic oxygen/methane fueled Mars Lander would require additional CFM surface technologies of in situ liquefaction, transfer and storage of these cryogens.

\section{Conclusion}

NASA's Cryogenic Fluid Management (CFM) Project, under the auspices of the Exploration Technology Development Program (ETDP), is focusing on the development of cryogenic storage systems, low-gravity propellant management systems, cryogenic transfer and handling technologies 
needed to provide necessary data and relevant experience to support informed decisions on implementation of cryogenic systems into the Space Exploration Architecture. This paper has organized Cryogenic Fluid Management Project technology efforts according to Exploration Architecture target areas, and has discussed the scope of trade studies, analytical modeling, and test efforts presently underway, as well as future plans, to address those target areas.

\section{References}

1. Tramel, T.L. and Motil, S.M., "NASA's Cryogenic Fluid Management Technology Project," AIAA2008-7622, 2008.

2. NASA Exploration Systems Architecture Study, NASA/TM-2005-214062, 2005.

3. Constellation Architecture Requirements Document (CARD), CxP 70000 Revision B, National Aeronautics and Space Administration, Release Date: 2/13/2008, 2008.

4. Dodge, F.T., "Dynamic Behavior of Liquids in Moving Containers," Southwest Research Institute, 2000. (An update of NASA SP-106)

5. Brakke, K.A., "The Surface Evolver Experimental Mathematics," Vol. 1, No. 2, pp. 141-165, 1992.

6. Grayson, G.D., Lopez, A., Chandler, F.O., Hastings, L.J., and Tucker, S.T., "Cryogenic Tank Modeling for the Saturn AS-203 Experiment," AIAA-2006-5258, 2006.

7. Grayson, G.D., Lopez, A., Chandler, F.O., Hastings, L.J., Hedayat A. and Brethour, J., "CFD Modeling of Helium Pressurant Effects on Cryogenic Tank Pressure Rise Rates in Normal Gravity," AIAA-2007-5524, 2007.

8. Lopez, A., Grayson, G.D., Chandler, F.O., Hastings, L.J. and Hedayat, A., "Cryogenic Pressure Control Modeling for Ellipsoidal Space Tanks," AIAA-2007-5552, 2007.

9. Lopez, A., Grayson, G.D., Chandler, F.O., Hastings, L.J. and Hedayat, A., "Cryogenic Pressure Control Modeling for Ellipsoidal Space Tanks in Reduced Gravity," AIAA-2008-5104, 2008.

10. Barsi, S. and Kassemi, M., "Numerical and experimental comparisons of the self-pressurization behavior of an LH2 tank in normal gravity." Cryogenics, Vol.48, pp.122-129, 2008.

11. Barsi, S., Panzarella, C.H. and Kassemi, M., "An Active Vapor Approach to Modeling Pressurization in Cryogenic Tanks," AIAA-2007-5553, 2007.

12. Barsi, S., Moder, J., and Kassemi, M., "Numerical Investigation of LO2 and LCH4 Storage Tanks on the Lunar Surface," NASA/TM-2008-215443, 2008.

13. Zimmerli, G.A., Vaden, K.R., Herlacher, M.D., Buchanan, D.A., and Van Dresar, N.T., "Radio Frequency Mass Gauging of Propellants," NASA/TM-2007-214907, 2007.

14. Hunter, G.W., Xu, J.C., Neudeck, D.B., Makel, D.B., Ward, B., and Liu, C.C., "Intelligent Sensor Systems for In-Space Applications," AIAA-2006-4356, 2006.

15. Jurns, J.M., "Visco Jet Joule-Thomson Device Characterization Tests in Liquid Methane," NASA/CR - 2009-215497, 2009 (Visco-Jet is a registered trademark of The Lee Company).

16. Moran, M.E., "Cryogenic Fluid Storage Technology Development: Recent and Planned Efforts at NASA," Joint Army Navy Air Force (JANNAF), 2008.

17. Flachbart, R.H., Hastings, L.J., Hedayat, A., Nelson, S.L., and Tucker, S.P., "Thermodynamic Vent System Performance Testing with Subcooled Liquid Methane and Gaseous Helium Pressurant," Cryogenics, 2008.

18. Grayson, G., "Pressure Control Data Correlation Option 2 Final Report, Rev. 1," Boeing report no. PWDM05-0038-42, The Boeing Company, March 31, 2009.

19. Jurns, J.M., McQuillen, J.B., "Bubble Point Measurements With Liquid Methane of a Screen Capillary Liquid Acquisition Device," Cryogenic Engineering Conference, 2007.

20. Hastings, L.J., Schunk, R.G., Grayson, G., Bolshinskiy, L.G., Martin, A.K., Eskridge, R.H., Pendletone, M.L., and Frenkel, A.L., "Marshall Space Flight Center feed system thermal integration for a cryogenic Lunar ascent stage," Space Cryogenics Workshop, 2009.

21. Wollen, M., Merino, F., Schuster, J., and Newton, C., "Cryogenic Propellant Management Device Conceptual Design Study," IES Report \#09-RPT-1004-ENG, 2009. 
22. Kontogiannis, G., Rudman, T., and Shepard, W., "Fluid management and propulsion experience from Titan IV/Centaur flights (TC-12 and TC-13)," AIAA-1996-2747, 1996.

23. Black, I.A., et al.; "Basic Investigation of Multilayer Insulation Systems," NAS3-4181, Arthur D. Little Inc. NASA CR-54191, October 1965.

24. "Advanced Studies on Multilayer Insulation Systems," NAS3-6283, Arthur D. Little Inc., NASA CR-54929, June 1966.

25. "Advanced Studies on Multilayer Insulation Systems," NAS3-7974, Arthur D. Little Inc., NASA CR-72368, January 1968.

26. "Investigation Regarding Development of a High Performance Insulation System," Lockheed Missiles and Space Co., NAS8-20758, LMSC Report K-17-68-5, July 1968.

27. Leonhard, K.E.; "Cryogenic Insulation Development (Phase II)," NAS8-18021, GDC-DDB69-002, December 1969.

28. Lofgren, C.L., Gieseking, D.E.; "Multilayer insulation Panels," NAS3-14179, Boeing NASA CR72857, April 1971.

29. Nies, G.E., "Light Weight Modular Multi-Layer Insulation," NAS3-12045, Linde Corp. NASA CR72856, June 1971.

30. Keler, C.W., "Thermal Performance of Multilayer Insulations," NAS3-12025, LMSC NASA CR72747, April 1971.

31. O'Neill, M.J., McDanal, A.J., "Study of Thermal Conductivity Requirements - Volume I, II, and III," NAS9-26189, LMSC HREC-6189-1, June 1971.

32. Shriver, C.R., et al., "Design Improvement, Qualification Testing, Purge and Vent Investigation, Fabrication and Documentation of a GAC-9 Insulation System," Goodyear GER-14915 S/9, November 1971.

33. Fredrickson, G.O., "Investigation of High Performance Insulation Application Problems," NAS821400, MACDAC MDC-G4722, August 1973.

34. Parmley, R.T., et al., "Effect of Environment on Insulation Materials," NAS3-14342, LMSC NASA CR 120978, February 1973.

35. Stochl, R.J., "Basic Performance of a Multilayer Insulation System Containing 20 to 160 Layers," NASA-LeRC TN D-7659, April 1974.

36. Walburn, A.B., "Design and Development of Pressure and Repressurizaton Purge System for Reusable Space Shuttle Multilayer Insulation Systems," NAS8-27419, GDC, CASD-NAS-74-032, August 1974.

37. Leonard, K.E., "Thermal Performance of a Customized Multilayer Insulation (MLI)," NAS3-17756, GDC NASA CR-135051, April 1976.

38. Knoll, R.H., DeWitt, R.L., "Thermal Performance of a Modularlized Replaceable Multilayer Insulation System for a Cryogenic Stage," NASA TN D-8282, January 1977.

39. Leonhard, K.E., "Develop and Demonstrate the Performance of Cryogenic Components Representative of Space Vehicles; Phase I Report - Concept Evaluation Coated Multilayer Insulation Materials," NAS8-31778, GDC CASD-NAS-78-009, November 1978.

40. Kramer, T.J., et al., "Evaluation of Propellant Tank Insulation Concepts for Low-Thrust Chemical Propulsion Systems," NAS3-22824, Boeing NASA CR-168320, March 1984.

41. Mohling, R.A., et al., "Multilayer Insulation Thick Blanket Performance Demonstration," F0461186-C-0122, Ball Aerospace Systems Group AFSC Report AL-RR-90-005, April 1990.

42. Martin, J.J., Hastings, L.J., "Large-Scale Liquid Hydrogen Testing of a Variable Density Multilayer Insulation With a Foam Substrate," NASA/TM-2001-21089, June 2001.

43. Hastings, L.J., et al., "Analytical Modeling and Test Correlation of Variable Density Multilayer Insulation for Cryogenic Storage," NASA/TM-2004-213175, May 2004.

44. Stark, J.A. and Blatt, M.H., "Cryogenic Zero-Gravity Prototype Vent System," NAS8-20146, Convair Report GDC-DDB67-006, October, 1967.

45. Sterbentz, W.H., "Liquid Propellant Thermal conditioning System," NAS3-7942, Lockheed Missiles \& Space Co. NASA CR-72113, April 1967. 
46. Bullard, B.R., "Liquid Propellant Thermal Conditioning System Test Program," NAS3-12033, Lockheed Missiles \& Space Co. NASA CR-72971, July 1972.

47. Erickson, R.C., "Space LOx Vent System," NAS8-26972, General Dynamics Convair Report CASD-NAS 75-021, April1975.

48. Sorensen, G.L., et al., "A Zero-Gravity Thermodynamic Vent System for the Shuttle/Centaur Hydrogen Tank," Intersociety Conference on Environmental Systems, July 1984.

49. Halsey, D., "A Zero-Gravity Thermodynamic Vent System for a Liquid Hydrogen Tank," Sunstrand Energy Systems Paper, undated.

50. Hastings, L.J., et al., "Spray Bar Zero-Gravity Vent System for On-Orbit Liquid Hydrogen Storage"; NASA/TM-2003-212926; October 2003.

51. Olsen, A.D., et al, "Solar thermal Upper Stage Cryogen System Engineering Checkout Test," AIAA Paper 99-2604, 35 ${ }^{\text {th }}$ Joint Propulsion Conference, Los Angeles, CA, June 20-23, 1999.

52. Flachbart, R.H., et al., "Testing of a Spray-Bar Thermodynamic Vent System in Liquid Nitrogen," 2005 Cyrogenic Engineering Conference, September 2005.

53. Hedayat, A., et al., "Liquid Nitrogen (Oxygen simulant) Thermodynamic Venting System Test Data Analysis," 2005 Cryogenic Engineering Conference, September 2005.

54. Flachbart, R.H., et al., "Zero Gravity Cryogenic Vent System Concepts for Upper Stages," Thermal \& Fluids Analysis Workshop, Huntsville, AL, September 13-17, 1999.

55. Hastings, L.J., et al., "Liquid Hydrogen Zero-Boiloff Testing and Analysis for Long-Term Orbital Storage," 2003 Cryogenic Engineering Conference, Anchorage, Alaska; September 22-26, 2003.

56. Gier, H.L., "Thermodynamic Vent Systems Optimization" Contract F04611-87-C-0053, Aerospace Design \& Development, Inc., AFAL-TR-88-001, March 1988.

57. Grayson, G.D., "Cryogenic Tank Modeling for the Saturn AS-203 Experiment," AIAA Paper 200065258, 42 ${ }^{\text {nd }}$ Joint Propulsion Conference, Sacramento, CA, July 9-12, 2006.

58. Grayson, G.D., Lopez, A., Chandler, F.O., Hastings, L.J., Hedayat A. and Brethour, J., "CFD Modeling of Helium Pressurant Effects on Cryogenic Tank Pressure Rise Rates in Normal Gravity," AIAA-2007-5524, 2007.

59. Lopez, A., Grayson, G.D., Chandler, F.O., Hastings, L.J. and Hedayat, A., "Cryogenic Pressure Control Modeling for Ellipsoidal Space Tanks," AIAA-2007-5552, 2007.

60. Lopez, A., Grayson, G.D., Chandler, F.O., Hastings, L.J. and Hedayat, A., "Cryogenic Pressure Control Modeling for Ellipsoidal Space Tanks in Reduced Gravity," AIAA-2008-5104, 2008.

61. Barsi, S. and Kassemi, M., "Numerical and experimental comparisons of the self-pressurization behavior of an LH2 tank in normal gravity." Cryogenics, Vol. 48, pp.122-129, 2008.

62. Barsi, S., Panzarella, C.H. and Kassemi, M., "An Active Vapor Approach to Modeling Pressurization in Cryogenic Tanks," AIAA-2007-5553, 2007.

63. VanOverbeke, T.J., "Thermodynamic Vent System Test in a Low Earth Orbit Simulation," NASA/TM-2004-213193 (2004)

64. Jurns, J.M., "Clogging of Joule-Thomson Devices in Liquid Hydrogen-Lunar Lander Descent Stage Operating Regime," Cryogenic Engineering Conference and International Cryogenic Materials Conference (2009)

65. Salerno, L.J., Gaby, J., Johnson, R., Kittel, P., and Marquardt, E., "Terrestrial Applications of Zero Boil-Off Cryogen Storage," in Cryocoolers 11 , proceedings of $11^{\text {th }}$ Int'1 Cryocooler Conference held June 20-22, 2000, Keystone, CO, Plenum Publishers, pp. 809, 2001. 
The public reporting burden for this collection of information is estimated to average 1 hour per response, including the time for reviewing instructions, searching existing data sources, gathering and maintaining the data needed, and completing and reviewing the collection of information. Send comments regarding this burden estimate or any olher aspect of this collection of information, including suggestions for reducing this burden, $t 0$ Departis control number.

TETURNYOUR FORMTOTHEABOVE ADDRESS.

\begin{tabular}{l|l|l|l} 
1. REPORT DATE (DD-MM-YYY) & 2. REPORT TYPE & 3. DATES COVERED (FrOm - TO)
\end{tabular}

01-02-2010

Technical Memorandum

4. TITLE AND SUBTITLE

Cryogenic Fluid Management Technology for Moon and Mars Missions

5a. CONTRACT NUMBER

5b. GRANT NUMBER

5c. PROGRAM ELEMENT NUMBER

\section{AUTHOR(S)}

Doherty, Michael, P.; Gaby, Joseph, D.; Salerno, Louis, J.; Sutherlin, Steven, G.

\section{5d. PROJECT NUMBER}

5e. TASK NUMBER

5f. WORK UNIT NUMBER

WBS 095240.04.03.01.03

\section{PERFORMING ORGANIZATION NAME(S) AND ADDRESS(ES)}

National Aeronautics and Space Administration

John H. Glenn Research Center at Lewis Field

Cleveland, Ohio 44135-3191

\section{SPONSORING/MONITORING AGENCY NAME(S) AND ADDRESS(ES)}

National Aeronautics and Space Administration

Washington, DC 20546-0001

\section{PERFORMING ORGANIZATION} REPORT NUMBER

E-17118

\section{SPONSORING/MONITOR'S ACRONYM(S) \\ NASA}

\section{SPONSORING/MONITORING} REPORT NUMBER

NASA/TM-2010-216070; AIAA-2009-

6532

\section{DISTRIBUTION/AVAILABILITY STATEMENT}

Unclassified-Unlimited

Subject Categories: 28,20 , and 14

Available electronically at http://gltrs.grc.nasa.gov

This publication is available from the NASA Center for AeroSpace Information, 443-757-5802

\section{SUPPLEMENTARY NOTES}

\section{ABSTRACT}

In support of the U.S. Space Exploration Policy, focused cryogenic fluid management technology efforts are underway within the National Aeronautics and Space Administration. Under the auspices of the Exploration Technology Development Program, cryogenic fluid management technology efforts are being conducted by the Cryogenic Fluid Management Project. Cryogenic Fluid Management Project objectives are to develop storage, transfer, and handling technologies for cryogens to support high performance demands of lunar, and ultimately, Mars missions in the application areas of propulsion, surface systems, and Earth-based ground operations. The targeted use of cryogens and cryogenic technologies for these application areas is anticipated to significantly reduce propellant launch mass and required on-orbit margins, to reduce and even eliminate storage tank boil-off losses for long term missions, to economize ground pad storage and transfer operations, and to expand operational and architectural operations at destination. This paper organizes Cryogenic Fluid Management Project technology efforts according to Exploration Architecture target areas, and discusses the scope of trade studies, analytical modeling, and test efforts presently underway, as well as future plans, to address those target areas. The target areas are: liquid methane/liquid oxygen for propelling the Altair Lander Ascent Stage, liquid hydrogen/liquid oxygen for propelling the Altair Lander Descent Stage and Ares V Earth Departure Stage, liquefaction, zero boil-off, and propellant scavenging for Lunar Surface Systems, cold helium and zero boil-off technologies for Earth-Based Ground Operations, and architecture definition studies for long term storage and on-orbit transfer and pressurization of $\mathrm{LH}_{2}$, cryogenic Mars landing and ascent vehicles, and cryogenic production via in situ resource utilization on Mars.

\section{SUBJECT TERMS}

Cryogenic fluids; Technology readiness; Lunar exploration; Mars exploration; Rocket propulsion systems; Surface systems; Ground operations

\begin{tabular}{|c|c|c|c|c|c|}
\hline \multicolumn{3}{|c|}{ 16. SECURITY CLASSIFICATION OF: } & \multirow{2}{*}{$\begin{array}{l}\text { 17. LIMITATION OF } \\
\text { ABSTRACT } \\
\text { UU }\end{array}$} & \multirow{2}{*}{$\begin{array}{l}\text { 18. NUMBER } \\
\text { OF } \\
\text { PAGES } \\
25\end{array}$} & \multirow{2}{*}{$\begin{array}{l}\text { 19a. NAME OF RESPONSIBLE PERSON } \\
\text { STI Help Desk (email:help@sti.nasa.gov) } \\
\text { 19b. TELEPHONE NUMBER (include area code) } \\
\text { 443-757-5802 }\end{array}$} \\
\hline $\begin{array}{l}\text { a. REPORT } \\
\mathrm{U}\end{array}$ & $\begin{array}{l}\text { b. ABSTRACT } \\
\text { U }\end{array}$ & $\begin{array}{l}\text { c. THIS } \\
\text { PAGE } \\
\text { U }\end{array}$ & & & \\
\hline
\end{tabular}



